\section{Einstein and the Nobel}

\section{Committee: Authority}

\section{vs. Expertise}

\author{
Robert Marc Friedman, \\ University of Oslo, Norway
}

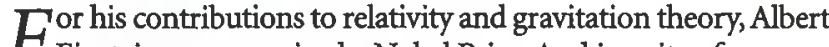
Einstein never received a Nobel Prize. And in spite of a popular misconception, spread especially through Abraham Pais' oft-cited but flawed account, Einstein did not receive a prize for his theory of the photoelectric effect. On September 6, 1922 the five Swedish members of the Nobel Committee for Physics proposed to the Royal Swedish Academy of Sciences that Einstein be awarded the previously reserved prize for 1921 for his discovery of the law of the photoelectric effect. In this year of celebrating Einstein, how should we reflect upon this paradox? An institution that is commonly accepted as a short-hand for supreme excellence in science ignored some of the most momentous accomplishments in the history of physics. Rather than rationalizing and seeking excuses, we might, in the spirit of Einstein, adopt a willingness to question established authority through reflection and insight.
\end{abstract}

\section{Committee Experimentalist Bias}

In the early decades of awarding the Nobel Prize, Swedish physicists with a strong experimentalist bias dominated the committee. They held precision measurement as the highest goal for their discipline; they favored candidates whose work mirrored their own orientations. Just as an experimental bias in the committee benefited some candidates, it also worked to the detriment of others. In 1911 new committee member Vilhelm Carlheim-Gyllensköld protested the minimal representation theoretical physics had received through the Nobel Prize. He stressed the neglect was not due to an absence of nominations for, since the beginning, prominent representatives had, in fact, been proposed, including Ludwig Boltzmann, Oliver Heaviside, Lord Kelvin, Max Planck, Henri Poncaré, and J. H. Poynting. Nevertheless, the committee continued to disregard the growing number of nominations for Planck and other theoretical physicists. Indeed the eventual prize to Planck in 1919 - the previously reserved 1918 prize - represented more a desire to acknowledge the leader of German science at a time of national tragedy than an embrace of early quantum theory. Some members of the committee at first proposed giving Johannes Stark the reserved 1918 prize and then the 1919 prize to Planck in order to underscore the greater importance of precision experiment over theoretical speculation. Of course the chronology of their respective achievements dictated otherwise.

For the Academy's scientists the emerging post-World War I era posed multiple hazards. The threat of socialism if not bolshevism, and a break-down in international relations within science were but some of the monsters swimming in this uncharted sea. The problematic hydra-headed beast of quantum and relativity theories that threatened what the Nobel committee frequently called "the common sense foundations of physics" continued to gain in strength during and immediately after the war. First the commit- tee had only Planck to contend with, but increasingly others entered the list of nominees enjoying serious support from nominators, such as Niels Bohr, Arnold Sommerfeld, and Einstein. Einstein's new general theory of relativity added yet further challenges to established modes of conceiving physical thought that began in 1905 with his special theory of relativity.

Those in the know understood the situation in Sweden was decidedly negative toward the latest advances in physics. The embarrassing delay in awarding Planck was but one indication. Apostles of the new physics who visited Sweden in 1919 noted little sympathy among senior scientists. Committee members Allvar Gullstrand and Bernhard Hasselberg could not follow much of the new physics based simply on their lack of training as well as disposition. Carlheim-Gyllensköld may have been sympathetic, but lacked skills to master the new. Gustaf Granqvist was too overwhelmed with work to follow the new developments for which he nevertheless had little enthusiasm. In contrast to the committee majority, Svante Arrhenius had no prior prejudice against theory taking an upper hand in the advance of science, but on matters that were at the limits of his understanding he frequently allowed calculation of interests and signals from his international contacts to dictate his position. The problem of recognizing the radical achievements in physics was not merely a question of individual beliefs and tastes, at the time committee members were also concerned with the image of physics, among other disciplinary issues. How the committee and Academy reacted to Einstein became a drama in several acts.

\section{0: A Surprise}

On November $6^{\text {th }} 1919$ at a joint meeting of the Royal Society of London and Royal Astronomical Society, the retired Cambridge physicist J. J. Thomson announced the results of the now-famous British eclipse expeditions. Thomson declared Einstein the winner. The ever so minute bending of starlight by the sun's mass was recorded on the photographic plates; the effect was declared real and not the result of random experimental error.

Sensational media coverage quickly transformed Einstein into a celebrity. In a Europe still recovering from the horror of world war and perplexed over the political and social upheavals in its wake, news of a revolutionary theory that claimed to overthrow the foundations of physics riveted media attention. Einstein himself was a sufficiently unorthodox figure in appearance, manner, and belief that the cult of relativity - and its sworn enemies gained yet further momentum from the man. Naturally many observers wondered whether Einstein would soon receive a Nobel Prize.

Einstein was no stranger to the Nobel committee. He had been nominated in 1910 when Wilhelm Ostwald proposed him for the special theory of relativity. In the years just before the war, Einstein received annual modest support from nominators. No doubt, nominators who might have been favorably disposed toward him were still trying to open the Nobel doors to theoretical physics with Planck. The committee merely claimed that Einstein's work needed to be followed to see if it possessed significance for physics.

Following the news of the eclipse results, nominators began to register the first aftershocks. Although still modest in number, nominations for Einstein dominated the sparse 1920 list. From the committee's perspective, the nomination from Niels Bohr might have been seen as one revolutionary thinker advocating the work of another intellectual radical, but others who proposed Einstein could scarcely have been more respectable. The elderly Berliner Emil Warburg, whose nominations frequently won committee respect, was one. Others included three Dutch laureates H. A. 
Lorentz, Heike Kamerlingh Onnes, and Pieter Zeeman. It is also possible that the revulsion scientists in Allied nations felt toward the German sweep of science prizes in 1919 - Planck, Stark, and Fritz Haber - prompted some nominators to turn to non-German candidates. Einstein heard rumors that he should not expect a prize in 1920 for political reasons.

Regardless, in its 1920 general report the committee dismissed Einstein, making but a minimal gesture in his direction. In a special report on the degree to which relativity theory had been confirmed, Arrhenius claimed that the British eclipse results cannot be admitted as evidence as questions remained about their degree of exactness. Arrhenius followed the skeptics' line that the margin of possible experimental error was larger than the effect that was to have been measured. Although acknowledging general relativity's success in accounting for the eccentricities in Mercury's orbit, he noted researchers' inability to find a shift toward the red end of the solar spectra. Arrhenius's report was decidedly tilted toward the negative opinions and interpretations in circulation. He duly noted J. J. Thomson and Arthur Eddington's points of reservation, but he did not include their widely quoted positive remarks. It seems he was trying to take cues from German scientists but which ones? He included the opinions of laureate Philipp Lenard, who along with Stark and other ultranationalists, were already endeavoring to discredit Einstein and relativity theory. For them, Einstein's wartime internationalist and pacifist stance was treason. His so-called Jewish-manner of practicing physics, based on flights of fantasy and self-promotion, threatened true German physics, grounded in experimental fact. This less-than-comprehensive report took little notice of what the nominators found valuable in Einstein's work. In fact, from the start it would seem the committee wanted the Nobel Prize in physics for 1920 to go to Charles-Edouard Guillaume.

Guillaume was the Swiss director of the French-based International Bureau of Weights and Measures. Guillaume devoted his career to improving the precision and reliability of standardized measurements. He had accidentally discovered a nickel-steel alloy that, unlike virtually all materials, was relatively unaffected by changes in its environment. He received but one nomination. His work and that of the bureau was of course valuable for science and its practical applications.

But in 1920, when the world of physics had entered upon an intellectual adventure of extraordinary proportions, it was remarkable to find Guillaume's accomplishment, based on routine study and modest theoretical finesse, recognized as a beacon of achievement. Even those who opposed relativity theory found Guillaume a bizarre choice. As one anti-relativist remarked to a Swedish colleague, whatever may be said about Einstein, he made his mark on physics; whereas Guillaume at best was marked by physics. Others, such as Sommerfeld, expressed disbelief. What then was going on?

Hasselberg, the Academy's professor of physics and member of the Nobel committee since its start in 1901, had been seriously ill for several years and was now about to retire. Hasselberg had previously championed works that reflected his own preference for precision measurement as the essential path to new insight in physics. After having maneuvered the 1907 prize to A. A. Michelson for his metrological work (basing the international meter on a natural constant), he asked like-minded colleagues abroad to nominate Guillaume. Not many others agreed with him. In 1920, the Swiss physicist, Charles Eugene Guye, nominated his countryman.

The bed-ridden Hasselberg wrote to the committee that he would be very happy to see Guillaume receive the prize. The

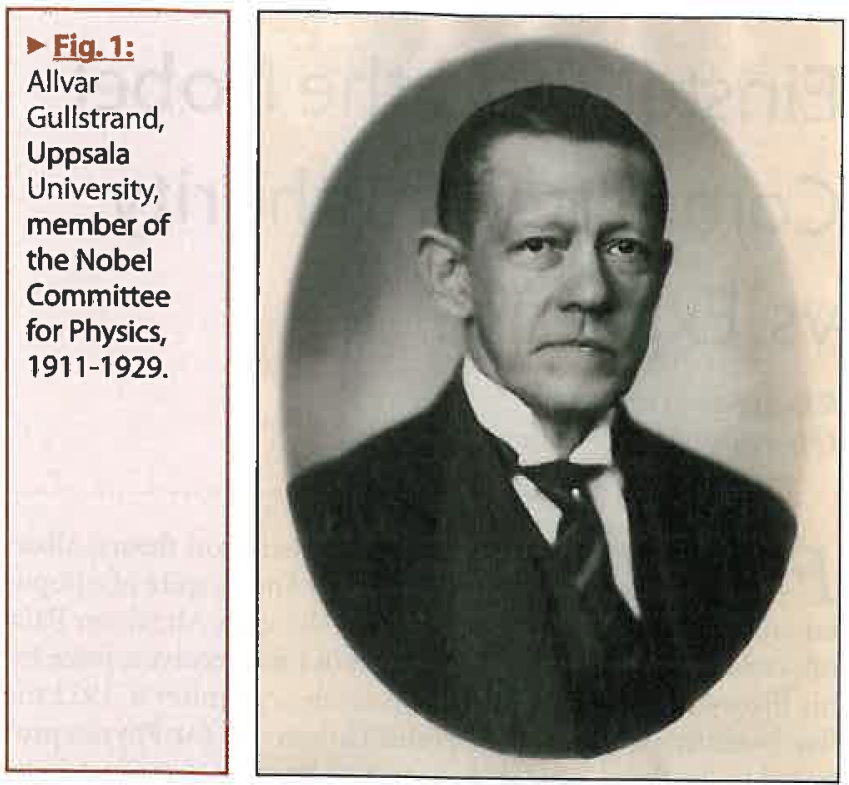

committee and then the Academy's vote delighted Hasselberg and of course Guillaume, who was as surprised as the rest of the world.

\section{1: Allvar Gullstrand vs. Albert Einstein}

In 1921, Einstein's place in physics received unambiguous confirmation. Nominations from England, Finland, France, Germany, Holland, and Sweden gave him broad international support. Einstein's position in the world of physics was portrayed by some nominators as being that of a giant, the likes of which had not been seen since Newton. Both theoreticians and experimentalists proposed Einstein, especially for his work on relativity and gravitation theory. Some claimed that it would be difficult to consider other candidates without first seeing Einstein recognized. No other candidate enjoyed anything resembling a mandate such as Einstein received.

When the Nobel committee for physics began assessing the nominations for the 1921 prize, Swedish Einstein-mania was in full bloom. As elsewhere, Einstein and relativity theory were emblematic of the new age of anxiety. Radicals proclaimed relativity as liberation from social, cultural, and intellectual traditions. Philosophers and cultural commentators feared that Einstein's theories implied a relativity of values. A few physicists borrowed the tone of the German attacks that began in earnest in 1920, but in contrast rarely invoked anti-Semitic slurs, at least in public. Of course, the snap, crackle, and pop of media noise need not have had any direct effect on the Nobel committee. But it seems that most committee members could scarcely conceive this bushyhaired, political and intellectual radical, who seemingly did not conduct experiments, crowned as the pinnacle of physics at a Nobel ceremony.

In 1921 Allvar Gullstrand took it upon himself to report on Einstein's contributions to relativity and gravitational theory. Gullstrand, who was one of the most distinguished members of the Academy, simply did not understand Einstein's work. Gullstrand embodied the best and worst of Uppsala's academic culture. In 1911 the physics committee was poised to award him its prize for his work on physiological optics, but the medical committee gave its prize to him first. Although a medical doctor by training, Gullstrand demanded and received a personal professorship as both ophthalmologist and physicist. In his path-breaking studies on the optics of the eye, and on astigmatism, Gullstrand 


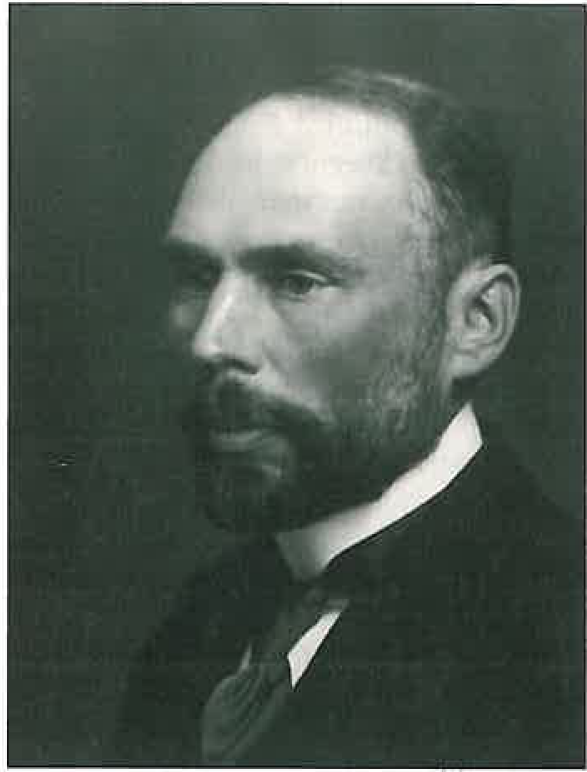

Tig. 2: Carl
Wilhelm
Oseen,
Uppsala
University/No
bel Institute
for
Theoretical
Physics, co-
opted
member of
the Nobel
Committee
for Physics,
1922 and
member
thereafter,
1923-1944.

developed his own intricate methods of analysis. When new advances in mathematics offered tools to simplify analysis, Gullstrand remained unmoved. His command of higher mathematics and theoretical physics was at best limited. Still he endeavored to join the physics committee. The Uppsala contingent in the Academy ensured Gullstrand's election.

Gullstrand demanded as much of himself as of others. He was fond of saying that: "a professor whose hands do not shake from exhaustion by the end of the academic year has not performed his duties properly." In a small, isolated but locally prestigious academic environment, arrogance, like mold in a damp cellar, tends to thrive. Arrogance prompted him to confront Einstein; to prove to the committee, the Academy, and Swedish society that relativity theory was of little significance. In the Academy, as elsewhere, titles and authority sometimes are mistaken for expertise.

Gullstrand had no intention of admitting relativity theory into the comprehensible world of physics. The theory's broader implications were troubling: Where is God in the fourth-dimension? Gullstrand insisted that the theory contained numerous errors. But his own critiques, both published and private, were shown to rest on mistaken understanding. No matter, he returned again and again with new objections.

Gullstrand's exceptionally long, fifty-page special report might appear at first glance to be comprehensive, but it was written from a basic premise: Einstein cannot be right. Gullstrand mobilized any negative claim, any article that was published in a scientific journal that provided alternative interpretations to those advanced by Einstein. His own analyses aimed at defusing those aspects of Einstein's theory that called for an overhaul of the "common sense foundations" of mechanics. According to Gullstrand that which remained once Einstein's errors and unproven assertions were eliminated, could best be treated successfully by classical mechanics. The British results were useless. Regardless, he rejected the suggestion that the bending of starlight by the sun can be regarded as a critical test for the theory, even if successfully demonstrated. Gullstrand maintained that classical aether physics might also explain this phenomenon. $\mathrm{He}$ concluded Einstein's theories did not possess "the significance for physics for which an awarding with a Nobel Prize can come into question."

Gullstrand had no trouble convincing his colleagues. No member had been convinced that the eclipse experiment yielded valid evidence. The remaining strong experimentalist core of the committee, Granqvist and Hasselberg, had little sympathy for Einstein's forceful use of theory. Hasselberg wrote from his sick bed, "it is highly improbable that [Alfred] Nobel considered speculations such as these to be the object of his prizes."

For the most critical Swedish opponents of Einstein, Hasselberg and Granqvist were seen as a bulwark keeping the Nobel Prize from promoting the further spread of the "diseased movement" of relativity. Hasselberg was not alone in expressing concern about the eroded foundations of European civilization; Bolshevism was a danger, poised to eradicate what was left of the prewar order. Einstein and his theory exemplified the erosion of past certainties; Dadaism in science standing in direct opposition to Truth, Beauty, and Goodness rooted in western civilization's classic Greek heritage.

When Gullstrand presented his report to the committee, nobody dissented. All agreed that no candidate could be identified as worthy; and therefore proposed to the Academy that the prize should be reserved until 1922 .

Gullstrand may have won the backing of the Academy's physicists, but he had not proved Einstein wrong. When the full Academy met to vote on the 1921 science prizes, a few solitary members questioned Gullstrand's evaluation. As usual no official account of the meeting exists, but a number of archival sources provide insight into the event. The Academy's discussion revealed gaps in Gullstrand's command of physics, as well as his prejudice. Some members understood that Einstein was more prominent than the Nobel Prize. Would it not be an embarrassment for the Academy not to recognize the man who had become the greatest scientific celebrity since Newton?

A decade earlier Gullstrand had compared each Nobel Prize to a Swedish flag that is visible to the entire world. For Gullstrand and many conservative members of the Academy the issue entailed whether the yellow and blue Swedish colours should be draped around a media-created sensational yet scientifically dubious theory? Gullstrand remarked privately, Einstein must never receive a Nobel Prize even if the whole world demanded it. In time he expected the theory and the mass-hysteria to fade away.

If the issue was simply Gullstrand's faulty evaluation, then in principle, the Academy was free to act once this was brought to light. But most members of the Academy had little inclination to give Einstein a Nobel Prize, and especially not for relativity, and no desire to slight its own esteemed member, Gullstrand. It mattered little that leading international physicists had praised Einstein as the greatest living representative of their discipline, and had declared his accomplishments in relativity theory to be among the most significant in the history of science. Local 'expertise' had spoken; the Academy guarded its own authority and its own right to assess and judge. The Academy voted not to award that year a Nobel Prize in physics.

\section{2: Enter Oseen}

The Academy of Science had once again made a statement. Those invited to nominate candidates for the two available physics prizes to be given in 1922 had to reflect on the meaning of this obvious rejection of Einstein. Could the Academy be persuaded to recognize Einstein, or would a proposal for him be a wasted nomination? Not sure how to second-guess the Academy's recent decisions, some nominators suggested a choice of alternate candidates. Einstein and his contributions to relativity theory still received overwhelming support.

Some also proposed Einstein for his contributions to quantum theory including the theory of the photoelectric effect. But, as in 


\section{Einstein's Triumph}

Humility ultimately vanquished arrogance, this time. Einstein might not have received the prize for his contributions to relativity theory, but he was soon able to have these celebrated in spite of the Academy. Einstein learned of the Academy's decision in a telegram that reached him while he was en route to Japan. He was relieved to receive the prize. He had been counting on it since 1918. At a time of decreasing value of the German Mark, he needed a hard currency to make alimony payments in Swiss Francs for his ex-wife and children living in Zurich. But he also was tired of being asked by journalists and others why he had not already received a Nobel Prize. It was the money that attracted him. Although he never expressed any special reverence to the Nobel Prize, Einstein later told a Swedish journalist that the prizes brought about a "social regulating" of age-old injustices. "Through the prizes scientists finally can harvest dividends from their work just like businessmen." And that made him happy.

Providentially, his trip to Japan would keep him away from the formal ceremonies of December. He could avoid the stiff formalities and media attention, both of which he loathed. Einstein undoubtedly found amusing the instructions informing him that when he delivered his Nobel lecture, he must lecture on the topic for which he has been awarded the prize: viz., no relativity. He arranged to hold his Nobel lecture the following summer. And he went not to Stockholm and the Academy, but to Sweden's second city, Gothenburg, where he addressed the $17^{\text {th }}$ Congress of Scandinavian Natural Scientists. Not being a formal Nobel ceremony, Einstein felt free to choose the topic for his lecture, or simply did not care. He spoke on recent developments in relativity theory. Sitting in the front row of the audience was one most attentive spectator who let it be known that he very much wanted to learn something of relativity theory: King Gustav Adolf $V^{\text {th }}$. On later occasions when Einstein drew up lists of his most important honours, he did not include the Nobel Prize.

\section{About the author}

Robert Marc Friedman is professor of history of science at University of Oslo. He acknowledges support from the National Science Foundation for research on the Nobel prizes. His publications include Appropriating the Weather: Vilhelm Bjerknes and the Construction of a Modern Meteorology and The Expeditions of Harald Ulrik Svedrup: Contexts for Shaping an Ocean Science. His play "Remembering Miss Meitner" was performed at Gothenburg Theatre, Swedish Broadcasting's Radiotheatre, and elsewhere, including at the 2004 International Nuclear Physics conference in Gothenburg. Another play, "Becoming Albert Einstein" opens in August in Bergen.

\section{Further Reading}

Full references to archival documents used in this summary can be found in:

Robert Marc Friedman, "Nobel physics prize in perspective", Nature, 292 (1981), 793-98.

Friedman, "Text, context, and quicksand: Method and understanding in studying the Nobel science prizes", Historical Studies in the Physical Sciences, 20 (1989), 63-78.

Friedman, The Politics of Excellence: Behind the Nobel Prize in Science (New York: Freeman/Times Books, 2001), Chapter 7.

Abraham Pais, "Subtle is the Lord....": The Science and Life of Albert Einstein (Oxford: Oxford University Press, 1982), Chapter 10.

\section{Doppler Tomography}

Tom Marsh,

Department of Physics, University of Warwick, Coventry CV4 7AL

$F^{\text {lattened disc-like structures are common throughout the }}$ $F$ Universe whenever matter has accumulated, for instance in the formation of stars and galaxies. Studies of these discs and related structures have benefited over the past two decades from an indirect imaging technique based upon medical Xray imaging called Doppler tomography. As will be described, this allows us to probe physical scales far below the reach of even the largest current telescopes.

\section{Accretion}

The Earth and other planets will continue to orbit the Sun until the Sun itself becomes a red giant some 7,000 million years hence. The outer planets and possibly the Earth too will survive beyond even this point as the Sun evolves to its final state as a small, dense star called a white dwarf. Although attracted towards the Sun, the planets never fall into it because they have angular momentum, and there is nothing, short of a passing star, that can remove it ${ }^{1}$. How then can the Sun and other stars ever have formed given that they had to coalesce from rotating clouds originally much larger than the Solar system?



A Fig. 1: Schematic pictures of a mass-transferring binary star with an accretion disc. A cool, tidally-distorted star (red) loses mass at the saddle-point in potential between the two stars. The gas forms a disc around the small hot, companion (blue).The compact star, the disc and the spot where the transferred matter hits the disc dominate the luminosity of these systems. The entire system shown here is comparable in size to the Sun; they have orbital periods which range from 10 minutes to 10 days.

'This is not quite true: gravitational radiation removes angular momentum, but so feebly as to be negligible over the lifetime of the Sun. 